\title{
Quantitative Genetic Analysis of Growth Rate in Avocado
}

\author{
Haofeng Chen ${ }^{1}$ \\ Department of Botany \& Plant Sciences, University of California, Riverside, CA 92521 \\ Vanessa E.T.M. Ashworth \\ Department of Ecology \& Evolutionary Biology, University of California, Irvine, CA 92697 \\ Shizhong Xu \\ Department of Botany \& Plant Sciences, University of California, Riverside, CA 92521 \\ Michael T. Clegg ${ }^{2}$ \\ Department of Ecology \& Evolutionary Biology, University of California, Irvine, CA 92697
}

\begin{abstract}
AdDitional INDEX words. Persea americana, 'Gwen' progeny, broad-sense heritability, flower abundance, fruit set
ABstract. The authors report a quantitative genetic analysis of avocado (Persea americana Mill.) growth rate, flower abundance, and fruit set. The data are based on a total of 204 different genotypes of progeny of 'Gwen' avocado. Each was replicated four times, with two replicates planted in each of two locations in southern California (Irvine and Riverside). Data were collected over 4 years (consecutive) on tree height, canopy diameter, and trunk diameter, representing three distinct measures of growth rate. Growth data were found to fit a linear regression over years, so the slope (growth rate) was used in the analyses. In addition, 2 years of data on flower abundance and 1 year on fruit set were also collected. Quantitative genetic analyses of these data showed that broad-sense heritability $(\mathrm{H})$ was $35.5 \%, 30.3 \%$, and $26.6 \%$ for tree height, canopy diameter, and trunk diameter respectively; and $33.8 \%$ and $23.0 \%$ for flowering abundance and fruit set respectively. No genotype-by-location effect was noted for growth rate; however, flower abundance and fruit set showed a relatively weak genotype-by-location effect $(\mathbf{2 1 . 9 \%}$ and $\mathbf{1 7 . 1 \%}$ respectively). The $\mathrm{H}$ estimates are low, probably as a result of sources of uncontrolled environmental error associated with variation in initial planting dates, but fall within the range that should permit quantitative trait locus analyses. The authors also found a moderate positive correlation between tree growth rates and fruit set, but none between growth rates and flower abundance. Different pollen parents have significantly different impacts on tree growth rates, flower abundance, and fruit set.
\end{abstract}

Avocado is one of the major fruit crops in the world. It is regarded as the most nutritious of all fruit and has a significant volume in international trade, with an estimated world production of 3.2 million Mg in 2005 (U.S. Department of Agriculture, 2006b). In the United States, avocado affords a significant income to producers each year (U.S. Department of Agriculture, 2006a).

Although avocado is a major subtropical tree crop and is important for human nutrition, genetic improvement of avocado is rudimentary, resulting from obstacles to breeding that are related to the biology of the avocado tree itself. As a consequence, the process of avocado breeding continues to rely on the selection of promising open-pollinated cultivars, without knowledge of the pollen source. Promising open-pollinated progeny are field tested, usually in several locations, but progress is slow and field testing is expensive and timeconsuming. Hybridization has played an important role in the origin of common avocado cultivars, many of which combine attributes from the three botanical races of avocado: the

Received for publication 28 Feb. 2007. Accepted for publication 27 June 2007. This work was supported by the California Avocado Commission.

We are grateful for the cooperation offered by Dr. M.L. Arpaia. We thank P. Robinson, D. Stottlemeyer, and E. Focht for their technical assistance, and we thank Z. Jia for analysis assistance.

${ }^{1}$ Current address: Department of Ecology \& Evolutionary Biology, University of California, Irvine, CA 92697

${ }^{2}$ Corresponding author. E-mail: mclegg@uci.edu.
Guatemalan, Mexican, and West Indian races. The Guatemalan race likely originated in upland Guatemala and includes cultivars with fruit distinctive by their thick, rough, green skin. Trees have acceptable cold tolerance, although inferior to that of trees belonging to the Mexican botanical race. Mexican race avocados are thought to have originated in upland Mexico, and their fruit are covered by thin, smooth, black skin. The fruit flesh is rich in oils that confer a superior sensory quality. Leaves of this race are strongly aromatic (anise scented) when crushed. The West Indian race, despite its name, is thought to have originated in lowland coastal Guatemala, is characterized by large fruit with a watery consistency and has salinity tolerance. Marked sensitivity to cold temperatures renders West Indian cultivars unsuitable for cultivation in California, and hence are of little relevance to the study reported here.

Major obstacles to the genetic improvement of avocado include the fact that a typical avocado tree produces more than one million tiny flowers, most of which abscise before fruit set, and only about $0.1 \%$ or fewer of flowers are destined to yield mature fruit (Davenport, 1986; Davis et al., 1998), so controlled pollination is virtually impossible. It is reported that even when an avocado tree is caged with a beehive, the exclusive formation of selfed progeny cannot be guaranteed (Degani et al., 2003). Second, the large size of avocado trees makes large-scale experimental trials labor intensive and expensive in land resources, and the widespread use of rootstocks introduces additional maintenance costs because the rootstock may 
overgrow the scion and requires vigilant pruning. Lastly, avocado trees are slow to mature, and reliable evaluation of fruit yield and quality is rarely obtained until 4 to 5 years after planting, and this induces high labor and land usage costs. The tools of modern genetics can be used to identify pollen donors retrospectively, to accelerate the breeding cycle and to improve breeding efficiency. However, implementation of these tools requires both an abundant supply of genetic markers and an improved understanding of the genetic determination of economically important traits.

Usually commercially important traits of avocado, such as tree growth rate, fruit precocity, fruit quality, flavor, and so on, are controlled by multiple genes, and those of large effect are called quantitative trait loci (QTLs). These traits are also influenced by environmental factors, so the genetic determination of phenotypic variation must be assessed using the statistical framework of quantitative genetics. Microsatellites [or simple sequence repeats (SSR)] provide an abundant supply of markers. Ashworth et al. (2004) developed 127 microsatellite markers for avocado and used a subset to study genetic relationships among avocado cultivars (Ashworth and Clegg, 2003). Thus the stage is set to apply marker-assisted selection on commercial traits such as fruit yield and quality, based on the association of QTLs with SSR markers.

As a first step in QTL detection we report a study based on clonal replicates of 204 progeny with the avocado cultivar Gwen as maternal parent and multiple pollen parents (mainly 'Bacon', 'Fuerte', and 'Zutano', according to this study) grown in two different locations in California. 'Gwen' is a cultivar that was selected from the University of California avocado breeding program. Its grandparent is believed to have been 'Hass', which likely derived from a cross of a Mexican type $\times$ Guatemalan type backcrossed to a Guatemalan-type avocado (H. Chen, P.L. Morrell, M. de La Cruz, and M.T. Clegg, unpublished). Genetic analyses suggest that the parent of 'Gwen' was 'Thille', a Guatemalan-type cultivar (Davis et al., 1998). 'Gwen' has similar flavor to 'Hass', but with higher yields and its fruit stores on the tree better (Bergh and Whitsell, 1982). 'Bacon', 'Fuerte', and 'Zutano' are all popular cultivars grown in California since the early 20th century. Knowledge of their history is largely anecdotal, but recent surveys of DNA sequence diversity, from a wide sample of wild and cultivated avocados, suggest that 'Fuerte' is a Mexicantype avocado, whereas 'Bacon', like 'Hass', is predominantly Guatemalan with about 20\% Mexican ancestry. 'Zutano' appears to have about equal Mexican and Guatemalan ancestries (H. Chen, P.L. Morrell, M. de La Cruz, and M.T. Clegg, unpublished). Figure 1 shows the photographs of fruit of these cultivars.

The phenotypic variance between trees of the same genotype provided an estimate of the environmental variance $\left(\mathrm{V}_{\mathrm{E}}\right)$. Broad-sense heritabilities $(\mathrm{H})$ were estimated by subtraction of $V_{E}$ from the total phenotypic variance taken across all trees $\left(\mathrm{V}_{\mathrm{P}}\right)$. These data also permitted the calculation of phenotypic correlations among traits such as growth rate, flower abundance, and fruit set. Lastly, estimates of the average effect of different pollen donors on each of these traits are reported.
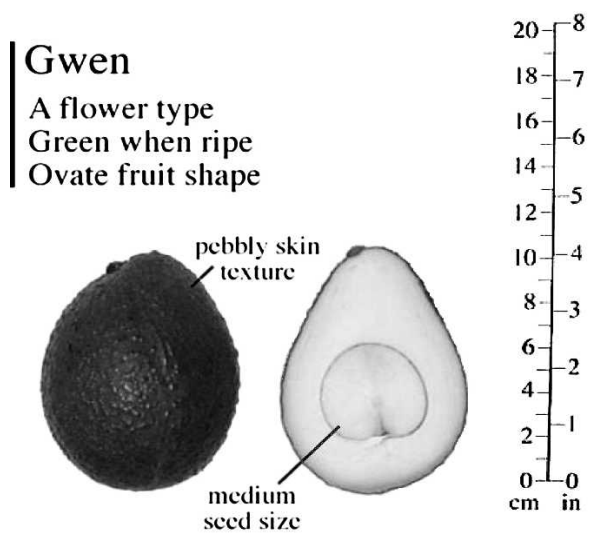

\section{Fuerte \\ "B" flower type \\ Green when ripe \\ Medium skin thickness}
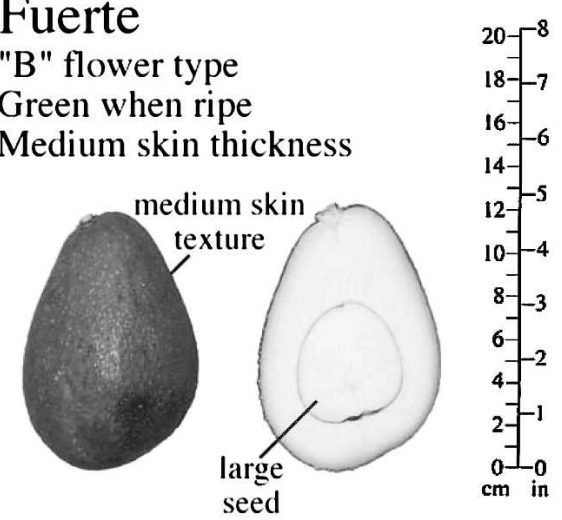

Fig. 1. The comparison of fruit shapes of avocado cultivars Gwen, Bacon, Fuerte, and Zutano. Photographs courtesy of M.L. Arpaia.
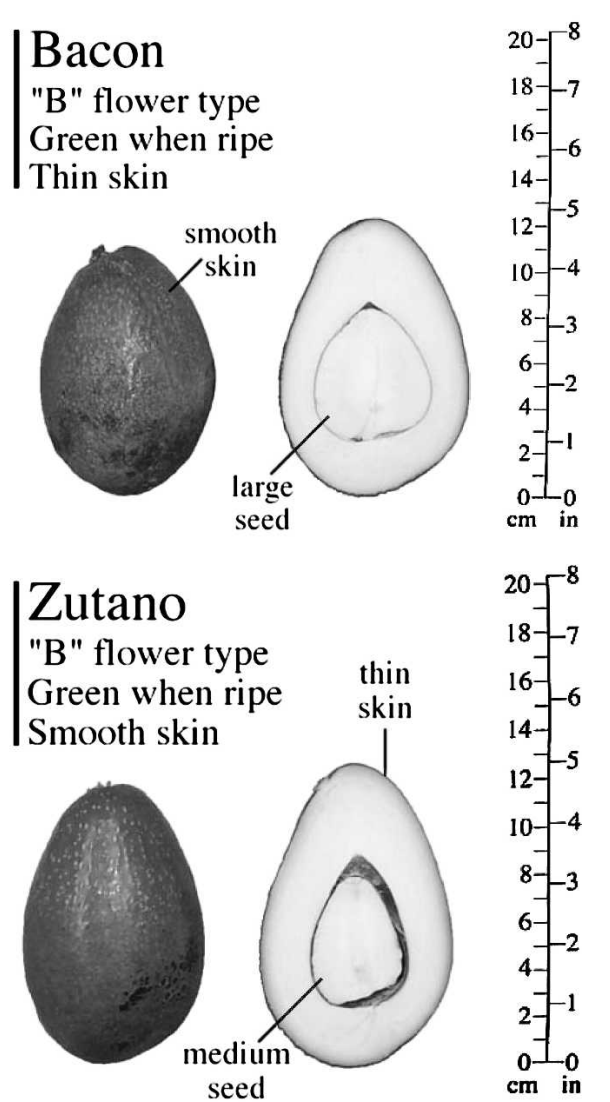

\section{Materials and Methods}

Plant materials

The experimental population consists of 204 seedling genotypes. The scions were trees from a source population growing at the University of California, Riverside, Agricultural Operations (AgOps) and represented the progeny of a single tree of cultivar Gwen (M.L. Arpaia and B.O. Bergh, pers. comm.). The seeds (fruit) from this 'Gwen' tree had been germinated and the resulting seedlings planted in a field at AgOps some 10 to 15 years previously. We took shoot cuttings from each tree in this source population and budgrafted them onto clonal 'Duke 7' rootstocks. ('Duke 7' is a widely used rootstock that has desirable disease resistance properties.) Four replicate grafts were made from each 'Gwen' progeny genotype, yielding a total of 816 trees.

Although records of the location of the 'Gwen' maternal tree have been lost, it was most likely growing at South Coast Research and Extension Center (SCREC), Irvine, CA. In addition to commercial avocado 
cultivars, this location is also home to an extensive avocado germplasm collection and avocado hedgerows used to shelter fields from the strong Santa Ana winds. The hedgerows are composed of trees discarded in the course of earlier breeding activities at the field station, and their origins and parentage are unknown.

\section{Experimental design}

The experimental trees were planted in 2001 and 2002 at two field locations, AgOps in Riverside and SCREC in Irvine, with two replicates of each genotype at each site. The replicated genotypes were planted in a randomized block design, with spacing between adjacent rows of $6.1 \mathrm{~m}$ and spacing between adjacent trees within one row of $4.6 \mathrm{~m}$. Irrigation water was determined using the irrigation calculator available on the California Avocado Commission website (California Avocado Commission, 2007) and administered via two microsprinklers per tree at $49.2 \mathrm{~L} \cdot \mathrm{h}^{-1}$ each. Fertilizer applications in late March/ early April involved a $15 \mathrm{~N}-6.5 \mathrm{P}-12.5 \mathrm{~K}$ granular formulation applied at a rate of $0.45 \mathrm{~kg} /$ tree [AgOps: fertilizer UN32 $(32 \mathrm{~N}-$ $0 \mathrm{P}-0 \mathrm{~K})$ was injected into the irrigation stream at $284.24 \mathrm{~L} \cdot \mathrm{ha}^{-1}$ in January]. Abamectin was applied in April to control avocado thrips (Scirtothrips perseae), and a fall/winter application of simazine and oryzalin controlled weeds (AgOps: simazine was applied preemergence in April and November, and glyphosate and oxyfluorfen were applied as needed). All other control/ husbandry procedures were also implemented as needed.

There are two important features of the experimental design in this study. First, it allows an estimation of the phenotypic variance within genotypes both within and between locations. These estimates provide a pure measure of the environmental (vs. genetic) variance. Estimating a location effect is very important because it tells the breeder whether a desirable phenotype will perform well over different environments. It also tells the breeder how predictable a desirable trait is over environments. Second, this design allows us to estimate the total degree of genetic determination $(\mathrm{H})$ of a desirable trait. A heritability of adequate magnitude is essential because traits with low $\mathrm{H}$ values will not respond efficiently to artificial selection.

The cultivar Gwen was used as the maternal parent because it is a highly adapted cultivar with good commercial promise. Owing to its origins through intervarietal hybridization, 'Gwen' also has substantial levels of heterozygosity for restriction fragment length polymorphisms (Davis et al., 1998) and microsatellite markers (Ashworth and Clegg, 2003), thus facilitating the long-term goal of associating SSR markers with the QTLs.

After some initial losses, mostly in 2001, 668 trees growing at Irvine and Riverside were available for measurement. A total of 95 distinct genotypes are represented by a full set of four replicates, three replicates remain for 78 genotypes, two replicates for 23 genotypes, and eight genotypes are each represented by a single tree.

\section{Measurement of avocado traits}

Beginning in Fall 2002 and continuing until Summer 2005, 4 consecutive years of data were collected from the experimental populations. The data include 1) tree height, measured from ground to treetop; 2) average canopy diameter, measured as the distance from the widest part of the tree canopy in two dimensions - parallel to the row and perpendicular to the row; 3) average tree trunk diameter, measured from about $10 \mathrm{~cm}$ above the ground in two perpendicular directions; 4) visual estimates of flower abundance (coded as 0 , none; 1 , a few; 2 , moderate; and 3, many); and 5) estimated fruit set (coded as 0 , none; 1, a few; 2, moderate; and 3, many).

\section{Identification of pollen donors from progeny simple sequence repeat genotypes}

Pollen parents of the 204 'Gwen' progeny genotypes were determined by assay of each progeny genotype for 10 microsatellite marker loci (AUCR418, AVD003II, AVD006, AVD013, AVD022, AVO102, AVT005b, AVT226, AVT386, and AVT436). Marker details (including primer sequences) and experimental conditions are described in Ashworth et al. (2004). All microsatellite genotypes were determined on an ABI3100 DNA sequencer and analyzed using GeneMapper version 4 (Applied Biosystems, Foster City, CA). Pollen donors were identified by comparison against a molecular reference collection of SSR genotypes for 38 avocado cultivars (V.E. Ashworth, unpublished data; Ashworth and Clegg, 2003).

\section{Quantitative genetic analysis}

Transformation OF TREE HEIGHT, CANOPY, AND TRUNK DIAMETER DATA INTO GROWTH RATES. Using PROC GPLOT Of SAS (version 9.1 for Windows; SAS Institute, Cary, NC), avocado height, canopy diameter, and trunk diameter data were plotted against the date when measurements were taken. Thus, time is the independent variable, and the growth rate of avocado is the dependent variable in the regression equation:

$$
\mathrm{Y}=\mathrm{b}_{0}+\mathrm{b}_{1} \mathrm{~T}+\varepsilon
$$

where $\mathrm{Y}$ is the matrix of measurement data for tree height/ canopy diameter/trunk diameter, $\mathrm{T}$ is the matrix of dates (the $\mathrm{n}^{\text {th }}$ month) when $\mathrm{Y}$ is measured, $\mathrm{b}_{0}$ is the intercept (the value when the first time measurement was taken), $b_{1}$ is the growth rate, and $\varepsilon$ is the matrix of random error to transform avocado growth rate (height, canopy diameter, and trunk diameter) into slope $b_{1}$. Estimates of $b_{1}$, the regression coefficient obtained from solving the linear transformation $b_{1}=\left(T^{\prime} T\right)^{-1}\left(T^{\prime} Y\right)$, yield the 4-year growth rate and these were used as trait values for quantitative genetic analyses. The relationship between growth rate and time fits a linear regression for the 4 years of early growth data (data not shown).

Heritability and correlations of avocado traits. We used the following analysis of variance (ANOVA) model to estimate $\mathrm{H}$ :

$$
\mathrm{Y}_{\mathrm{ijkr}}=\mu+\mathrm{D}_{\mathrm{i}}+\mathrm{G}_{\mathrm{j}(\mathrm{i})}+\mathrm{L}_{\mathrm{k}}+\mathrm{D}_{\mathrm{i}} \times \mathrm{L}_{\mathrm{k}}+\mathrm{G}_{\mathrm{j}(\mathrm{i})} \times \mathrm{L}_{\mathrm{k}}+\varepsilon_{\mathrm{r}(\mathrm{ijk})}
$$

where $\mathrm{Y}$ is the growth rate of an individual tree; $\mu$ is the mean of all trees' growth rate; $\mathrm{D}$ is the effect of pollen donors $[\mathrm{i}=\mathrm{B}$ ('Bacon'), F ('Fuerte'), Z ('Zutano'), M (mixed)]; G is the effect of different genotypes; $\mathrm{j}$ is equal to $1,2 \ldots 204$; $\mathrm{L}$ is effect by location, $\mathrm{k}$ is the location (Riverside, Irvine); $\mathrm{D} \times \mathrm{L}$ is the effect of pollen donor and location interaction; $\mathrm{G} \times \mathrm{L}$ is the effect of genotype and location interaction; $\varepsilon$ is the residual error; and $r$ is equal to 1 or 2 .

In this analysis, $\mathrm{G}$ and $\mathrm{G} \times \mathrm{L}$ were treated as random effects, and all other components were treated as fixed effects. The expected mean square (MS) of genotype was given by

$$
\mathrm{E}\left(\mathrm{MS}_{\mathrm{G}}\right)=\sigma_{\mathrm{E}}^{2}+\mathrm{K}_{1} \sigma_{\mathrm{G} \times \mathrm{L}}^{2}+\mathrm{K}_{2} \sigma_{\mathrm{G}}^{2}
$$

and the MS of genotype $\times$ location was given by 


$$
\mathrm{E}\left(\mathrm{MS}_{\mathrm{G} \times \mathrm{L}}\right)=\sigma_{\mathrm{E}}^{2}+\mathrm{K}_{3} \sigma_{\mathrm{G} \times \mathrm{L}}^{2}
$$

Then the broad-sense heritability can be calculated as

$$
\mathrm{H}=\sigma_{\mathrm{G}}^{2} /\left(\sigma_{\mathrm{G}}^{2}+\sigma_{\mathrm{G} \times \mathrm{L}}^{2}+\sigma_{\mathrm{E}}^{2}\right)
$$

where $\sigma^{2}{ }_{\mathrm{G}}$ is the genotypic variance, $\sigma_{\mathrm{G}}^{2} \times \mathrm{L}$ is the variance incited by genotype by location interaction, and $\sigma^{2}$ is the variance incited by error. All null hypotheses were tested by $\mathrm{F}$ test from the ANOVA table of PROC GLM type III sum of squares (SAS, version 9.1), and the significance level was set to $P=0.05$. The correlations among tree growth rate, fruit set and flower abundance were estimated using PROC CORR analysis (SAS, version 9.1), and the individual effects of different pollen donors on tree growth rate, flower and fruit set were estimated using the MEANS statement of PROC GLM, and the significance tests were done using the post hoc test of StudentNewman-Keuls (SAS, version 9.1).

\section{Results and Discussion}

Determination of POLLEN donors. The SSR marker analyses revealed that all but one of the 204 progeny genotypes arose from outcrossing (i.e., the pollen came from sources other than 'Gwen') and that 146 of the 204 genotypes have the common cultivars Bacon, Fuerte, or Zutano as their male parents. Of these, 49 genotypes have 'Bacon' as their pollen donor, 53 have 'Fuerte', and 44 have 'Zutano'. For the remaining 58 genotypes, most pollen parents did not correspond to any of the cultivars included in our molecular reference archive (V.E. Ashworth, unpublished data; Ashworth and Clegg, 2003) and may be regarded as an open population of pollen, most likely originating from adjacent hedgerow avocados or germplasm cultivars not included in our reference archive. For the quantitative analysis, the unidentified donor cohort was grouped into the "mixed pollen donor group" (including the one selfed genotype). In total there are thus four pollen donor subgroups "B" ('Bacon'), "F" ('Fuerte'), " $Z$ ", ('Zutano'), and "M" (mixed).

ESTIMATION OF BROAD-SENSE HERITABILITY AND GENOTYPE-BYLOCATION INTERACTIONS. The partition of variance in genotype $(\mathrm{G})$, the interaction $(\mathrm{G} \times \mathrm{L})$, and residual error of cultivar Gwen progeny growth rate, flower abundance, and fruit set are shown in Table 1, and broad-sense heritabilities are listed in Table 2. Except for fruit set $(\mathrm{H}=0.230)$, heritabilities of all other traits are in the medium range, around 0.30 . These estimates are relatively low compared with similar traits in other plant and animal species, perhaps because of environmental differences between the locations, the different planting times of trees, and the low level of genotype replication in the two locations. The low heritability of fruit set may be also incited by limited data (only 1 year of data available). Genotype-by-location interactions in tree growth rate for height, canopy diameter, and trunk diameter are small and nonsignificant. However there are low but significant location interactions for flower abundance and fruit set (Table 2).

There are relatively few estimates of the heritability of growth rate for trees and especially for fruit trees. Those studies that exist include scots pine (Pinus sylvestris L.) (Ericsson and Fries, 2004; Jansson et al., 2003; Persson and Andersson, 2003), loblolly pine (Pinus taeda L.) (Gwaze et al., 2002), and white spruce [Picea glauca (Moench) Voss] (Yu et al., 2003; Zhang et al., 2004). Narrow-sense heritability $\left(\mathrm{h}^{2}\right)$ from these species varies from 0.0 to 0.62 , but most values are less than 0.30 .

Our estimates of broad-sense heritability from avocado trees fall in the mid range of previous results based on conifers.

Correlation among Traits. The three tree growth rates-height, canopy diameter, and trunk diameter-have high positive correlations, whereas fruit set has a medium positive correlation with the growth rates (0.41-0.52; Table 3$)$. Flower abundance is not correlated with growth rate, and there

Table 1. Analysis of variance of tree growth rate, flower abundance, and fruit set for the progeny of 'Gwen' avocado.

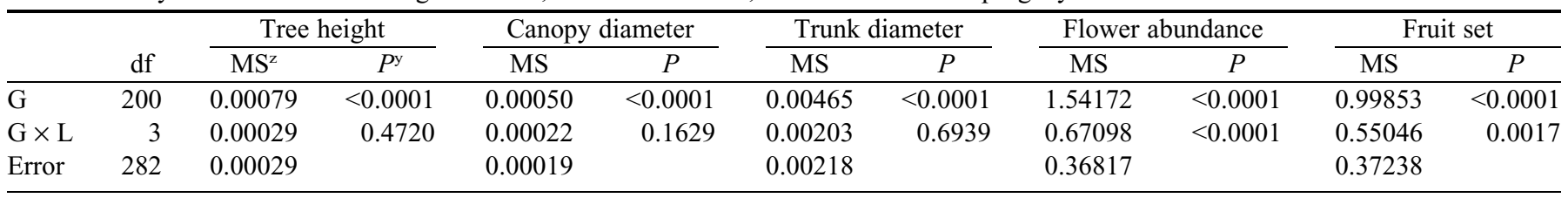

${ }^{\mathrm{z}} \mathrm{MS}$, mean square.

The treatment effects are tree genotype $(\mathrm{G})$, genotype-by-location interaction $(\mathrm{G} \times \mathrm{L})$, and residual error.

Table 2. Broad-sense heritability $(\mathrm{H})$ of growth rate, flower abundance, and fruit set of the progeny of 'Gwen' avocado and genotype-by-location interactions.

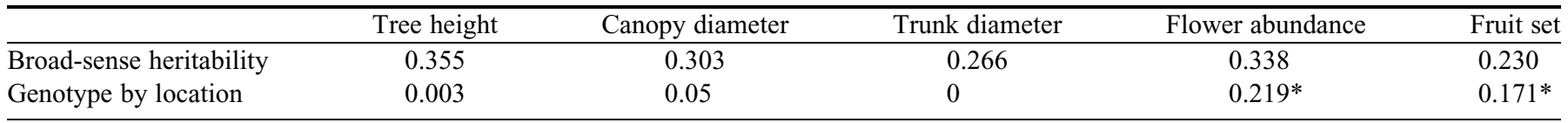

*Significant at $P<0.05$.

Table 3. Correlation among growth rate, flower abundance, and fruit set of the progeny of 'Gwen' avocado.

\begin{tabular}{lccrr}
\hline & Tree height & Canopy diameter & Trunk diameter & Flower abundance \\
\hline Tree height & 1 & $0.681^{* * *}$ & $0.662^{* * *}$ & 0.095 \\
Canopy diameter & 1 & $0.665^{* * *}$ & 0.089 & $0.524^{* * *}$ \\
Stem girth & & 1 & 0.081 & $0.488^{* * *}$ \\
Flower abundance & & & 1 & $0.411^{* * *}$ \\
Fruit set & & & $0.179^{* * *}$ \\
\hline
\end{tabular}

***Significant at $P<0.001$. 
Table 4. Mean effects of different pollen donors upon growth rate (tree height, canopy diameter, trunk diameter), flower abundance, and fruit set of the progeny of 'Gwen' avocado.

\begin{tabular}{lcccc}
\hline Pollen donor & $\begin{array}{c}\text { Tree height } \\
(\mathrm{cm} / \text { month })\end{array}$ & $\begin{array}{c}\text { Canopy diameter } \\
(\mathrm{cm} / \mathrm{month})\end{array}$ & $\begin{array}{c}\text { Trunk diameter } \\
(\mathrm{cm} / \text { month })\end{array}$ & $\begin{array}{c}\text { Flower abundance } \\
(0-3-\mathrm{pt} \mathrm{scale})^{\mathrm{z}}\end{array}$ \\
\hline Bacon & $6.081 \mathrm{a}$ & $6.142 \mathrm{~b}$ & $0.226 \mathrm{a}$ & $1.868 \mathrm{a}$ \\
Fuerte & $5.367 \mathrm{~b}$ & $6.732 \mathrm{a}$ & $0.218 \mathrm{a}$ & $1.392 \mathrm{~b}$ \\
Zutano & $6.297 \mathrm{a}$ & $5.927 \mathrm{~b}$ & $0.216 \mathrm{a}$ & $1.741 \mathrm{ab}$ \\
Mixed donor & $5.945 \mathrm{a}$ & $6.171 \mathrm{~b}$ & $0.214 \mathrm{a}$ & $1.497 \mathrm{~b}$ \\
\hline
\end{tabular}

${ }^{\mathrm{z}} 0=$ none, 1 = a few, 2 = moderate, 3 = many.

y In each column, means followed by the same letter were not significantly different using the Student-Newman-Keuls test at $P<0.05$.

Table 5. Mean effects of different locations upon growth rate (tree height, canopy diameter, trunk diameter), flower abundance, and fruit set of the progeny of 'Gwen' avocado.

\begin{tabular}{|c|c|c|c|c|c|}
\hline & $\begin{array}{l}\text { Tree height } \\
(\mathrm{cm} / \text { month })\end{array}$ & $\begin{array}{l}\text { Canopy diameter } \\
(\mathrm{cm} / \text { month })\end{array}$ & $\begin{array}{l}\text { Trunk diameter } \\
(\mathrm{cm} / \mathrm{month})\end{array}$ & $\begin{array}{c}\text { Flower abundance } \\
(0-3-p t \text { scale })^{z}\end{array}$ & $\begin{array}{c}\text { Fruit set } \\
(0-3-\text { pt scale })^{z}\end{array}$ \\
\hline Irvine, CA & $7.267 \mathrm{a}^{\mathrm{y}}$ & $7.390 \mathrm{a}$ & $0.237 \mathrm{a}$ & $1.818 \mathrm{a}$ & $1.849 \mathrm{a}$ \\
\hline Riverside, CA & $4.014 \mathrm{~b}$ & $4.646 \mathrm{~b}$ & $0.193 \mathrm{~b}$ & $1.444 \mathrm{~b}$ & $0.885 \mathrm{~b}$ \\
\hline
\end{tabular}

${ }^{\mathrm{z}} 0=$ none, 1 = a few, 2 = moderate, 3 = many.

${ }^{\mathrm{y}}$ In each column, means followed by the same letter were not significantly different using the Student-Newman-Keuls test at $P<0.05$.

is a low positive correlation with fruit set. This suggests that selection on trees for high growth rate may also lead to enhanced fruit set.

THE EFFECT OF DIFFERENT POLLEN DONORS ON GROWTH RATE. When the growth rate data were partitioned by pollen donors ['Bacon', 'Fuerte', 'Zutano', and "mixed" (Table 4)], we found that progeny pollinated by 'Fuerte' are significantly slower in mean height growth than the progeny from the other categories, but their mean canopy diameter is significantly larger than other progeny. With regard to tree trunk diameter, all pollen parents had similar effects. Progeny pollinated by 'Zutano' had a significantly higher mean tree height growth rate and fruit set than progeny with the other paternal origins, but they had slower growth rates for canopy diameter. 'Bacon' progeny exhibited a fast growth rate for height, trunk diameter, and high flower abundance, but had only a low fruit set and low flower abundance. Progeny from pollen parents in the "mixed" category have relatively high growth rate on tree height, moderate canopy diameter and flower abundance, but they were lowest in fruit set.

EFfect of location: Irvine Versus Riverside. When the data are partitioned by location (Table 5), we found an effect of location on growth rate, flower abundance, and fruit set. The growth rate in Irvine is higher than in Riverside, and also trees in Irvine produce more flowers and fruit than those in Riverside. This result may be incited by the difference in climate and soil quality in these two places and by differences in planting times. Riverside has a more extreme climate than Irvine, with hotter summers, colder winters, and lower humidity and the soil is more sandy.

\section{Future Directions}

The 'Gwen' progeny trees continue to be the focus of our data collection activities, with emphasis over recent growing seasons on attributes of the fruit. Data on tree shape and tolerance of freezing temperatures (during the freeze of midJan. 2007) have also been obtained. All data will be fed into a QTL analysis in the hope of detecting associations between our genetic markers and the phenotypic traits in question. Data collection will be continued with a view to compiling data points over multiple years. Ultimately, a subset of the 'Gwen' progeny trees will form the nucleus of one or more rounds of marker-assisted selection and, hopefully, elite selections or commercially valuable breeding material will result.

\section{Conclusion}

The heritability values for avocado traits estimated in this study are of moderate to low magnitude, but within the range suitable for successful artificial selection. The growth rates of avocado for height, canopy diameter, and trunk diameter are highly positively correlated with each other, and they are also correlated with fruit set. Different pollen parents have different impacts on growth rate, flower abundance, and fruit set; and there is also evidence of a location effect on avocado traits.

\section{Literature Cited}

Ashworth, V.E.T.M. and M.T. Clegg. 2003. Microsatellite markers in avocado (Persea americana Mill.): Genealogical relationships among cultivated avocado genotypes. J. Hered. 94:407-415.

Ashworth, V.E.T.M., M.C. Kobayashi, M. de La Cruz, and M.T. Clegg. 2004. Microsatellite markers in avocado (Persea americana Mill): Development of dinucleotide and trinucleotide markers. Sci. Hort. 101:255-267.

Bergh, B.O. and R.H. Whitsell. 1982. Three new patented avocados. California Avocado Soc. Yearbook 66:51-56.

California Avocado Commission. 2007. Irrigation calculator. 2 Apr. 2007. <www.avocado.org/growers/irrigcalc.php>.

Davenport, T.L. 1986. Avocado flowering. Hort. Rev. (Amer. Soc. Hort. Sci.) 8:257-289.

Davis, J., D. Henderson, M. Kobayashi, M.T. Clegg, and M.T. Clegg. 1998. Genealogical relationships among cultivated avocado as revealed through RFLP analysis. J. Hered. 89:319-323.

Degani, C., E. Lahav, R. El-Batsri, and S. Gazit. 2003. Caging single avocado trees with a beehive does not guarantee exclusive formation of selfed progeny. HortScience 38:1433-1434.

Ericsson, T. and A. Fries. 2004. Genetic analysis of fiber size in a fullsib Pinus sylvestris L. progeny test. Scand. J. For. Res. 19:7-13.

Gwaze, D.P., K.J. Harding, R.C. Purnell, and F.E. Bridgwater. 2002. Optimum selection age for wood density in loblolly pine. Can. J. For. Res. 32:1393-1399. 
Jansson, G., B.L. Li, and B. Hannrup. 2003. Time trends in genetic parameters for height and optimal age for parental selection in scots pine. For. Sci. 49:696-705.

Persson, T. and B. Andersson. 2003. Genetic variance and covariance patterns of growth and survival in northern Pinus sylvestris. Scand. J. For. Res. 18:332-343.

U.S. Department of Agriculture. 2006a. Avocado situation and outlook for selected countries. 2 Apr. 2007. <www.fas.usda.gov/htp/ Hort_Circular/2006/05-06/Avocados\%205-10-06.pdf>.
U.S. Department of Agriculture. 2006b. Commodity highlight: Avocados. 2 Apr. 2007. <www.ers.usda.gov/briefing/fruitandtreenuts/ fruitnutpdf/Avocado.pdf $>$.

Yu, Q.B., D.Q. Yang, S.Y. Zhang, J. Beaulieu, and I. Duchesne. 2003. Genetic variation in decay resistance and its correlation to wood density and growth in white spruce. Can. J. For. Res. 33:2177-2183.

Zhang, S.Y., Q.B. Yu, and J. Beaulieu. 2004. Genetic variation in veneer quality and its correlation to growth in white spruce. Can. J. For. Res. 34:1311-1318. 